\section{LA EXPULSIÓN DE LOS JESUITAS DE PORTUGAL EN LA “ERA POMBALINA"}

\author{
Borja Vivanco Díaz \\ Comisión de Identidad y Misión (I+M) del Consejo de Gobierno \\ de la Universidad de Deusto \\ bovivanco@yahoo.es
}

Cómo citar este artículo/Citation: Vivanco Díaz, B. (2014). "La expulsión de los jesuitas de Portugal en la 'era pombalina'”. Arbor, 190 (766): a110. doi: http://dx.doi.org/10.3989/ arbor.2014.766n2002

Recibido: 4 febrero 2014. Aceptado: 12 abril 2014.

RESUMEN: Los jesuitas fueron expulsados de Portugal en 1759 como consecuencia de la política "regalista" del "despotismo ilustrado" y a la que se había adherido sin reservas el Marqués de Pombal, primer ministro del rey José I. Las acusaciones de instigar a los guaraníes a rebelarse contra el Tratado de los Límites, por un lado, y de conspirar en la organización del atentado frustrado contra la vida de José I, por otro, sirvieron de argumentos para provocar el exilio de la Compañía de Jesús. Sin embargo, ninguna de las dos acusaciones ha podido ser nunca probada y respondieron más bien a la campaña "pombalina" contra la orden de Ignacio de Loyola. Como resultado final, la expulsión de los jesuitas aminoró la influencia de la Iglesia Católica y favoreció la introducción en Portugal de las nuevas ideas de la llustración.

PALABRAS CLAVE: Despotismo ilustrado; jesuitas; Ilustración; José l; Marqués de Pombal; Portugal; regalismo; reducciones; Tâvora.

\section{THE EXPULSION OF JESUITS FROM PORTUGAL IN THE "POMBALINE ERA"}

Copyright: ( 2014 CSIC. Este es un artículo de acceso abierto distribuido bajo los términos de la licencia Creative Commons Attribution-Non Commercial (by-nc) Spain 3.0.
ABSTRACT: The Jesuits were expelled from Portugal in 1759 as a consequence of Regalian policy of enlightened despotism, which had been wholeheartedly accepted by Marquis of Pombal, prime-minister under the King Joseph I. Accusations of inciting the Guarani people to rise up against "The Treaty of the borders", on the one hand, and of conspiring in the assassination attempt against King Joseph I, on the other, supported the decision to force the Jesuits into exile. However, neither allegation has been ever proven, rather they were the result of Pombal's campaign against Saint Ignatius of Loyola's order. The ultimate outcome of the expulsion of the Jesuits was the diminished influence of Catholic Church, thus encourating the introduction of new Enlightenment ideas in Portugal.

KEYWORDS: enlightened despotism; Jesuits; Enlightenment; Joseph I; Marquis of Pombal; Portugal; regalism; reductions; Tâvora. 


\section{INTRODUCCIÓN}

En 1759, y a instancias del Marqués de Pombal (1699 - 1782), el rey José I (1714 - 1777) decretó la expulsión de los jesuitas de todos los dominios del imperio portugués. A nadie cogió de sorpresa la decisión del monarca luso, si bien hasta ese momento nunca un reino católico se había atrevido a disolver una institución eclesiástica tan señera. Pero desde hacía aproximadamente una década, una serie de acontecimientos que se vivieron en la corte y la vida política de Portugal tensaron, hasta el borde del precipicio, las relaciones entre la monarquía y la Compañía de Jesús.

A través del presente artículo vamos a estudiar las razones y determinar los sucesos que llevaron al rey José I al hecho inédito de expulsar, fuera de Portugal, a la orden religiosa de Ignacio de Loyola. Fue una decisión de gran trascendencia histórica y que superó, con creces, las fronteras del imperio luso, ya que enseguida los reinos borbones siguieron el ejemplo del rey portugués: Los jesuitas fueron expulsados sucesivamente de Francia (1762), de España y Nápoles (1767) y del ducado de Parma (1768).

Ciertamente el "antijesuitismo"1 se había convertido en doctrina política y, más en concreto, en baluarte del "despotismo ilustrado" de las cortes católicas. A mitad del siglo XVIII, los conflictos entre las monarquías católicas y la orden de Ignacio de Loyola fueron a constituir una de las realidades más notorias de la actualidad política europea. Puede llegar a afirmarse que, desde la época de la extinción de los caballeros templarios a principios del siglo XIV, ninguna orden había sido víctima de semejante persecución en los reinos católicos. Y al final el débil y presionado Papa Clemente XIV promulgó la supresión de la Compañía de Jesús en $1773,{ }^{2}$ con el breve Dominus ac Redemp$t^{3} r^{3}$ y con el respaldo de no pocos cardenales y obispos. ${ }^{4}$ Únicamente Austria era la única de las grandes monarquías católicas que, en ese momento, no había expulsado a los jesuitas de su territorio.

En el "Siglo de las Luces", la Compañía de Jesús era sin duda el instituto religioso más influyente de la Iglesia Católica. Lo era posiblemente ya al poco tiempo de su fundación, datada en las primeras décadas del siglo XVI y en el contexto histórico y singular de la "era de los descubrimientos", el Renacimiento y el Humanismo, la Reforma protestante y la Contrarreforma católica.

Hay que tener en cuenta que a diferencia de lo que era y es usual en el conjunto de los institutos religiosos, la labor apostólica de la Compañía de Jesús se ex- tendía a multitud de campos. Entre otros ministerios, los jesuitas eran intrépidos misioneros en los territorios más remotos, servían de "confesores" de reyes y aristócratas o se dedicaban a la enseñanza y al trabajo intelectual en prestigiosos colegios y universidades.

Recordemos que la Compañía de Jesús se hizo presente en Portugal desde el primer momento y constituyó uno de los pilares de influencia de la Iglesia Católica. Uno de los seis estudiantes universitarios que -liderados por Ignacio Loyola - profesaron sus votos en Montmarte (París) en 1534 y cofundaron así la Compañía de Jesús era un joven lusitano: Simón Rodrigues de Azevedo. Él fue quien fundó, además, la provincia jesuita de Portugal que conoció un amplio desarrollo gracias a la simpatía que despertó en la corte; si bien Rodrigues e Ignacio de Loyola vivieron entre sí tensiones de calado (Alonso Romo, 2005). En cualquier caso, podría llegar a afirmarse que los comienzos de la orden de los jesuitas fueron brillantes en Portugal. En 1553, tres años antes de la muerte de Ignacio de Loyola, había ya 318 jesuitas en Portugal (Aguirre Beltrán, 1999, 37). Además, en 1541 y con el decidido respaldo del rey lusitano Juan III (conocido como "El Piadoso"), Francisco de Javier partió de Lisboa para evangelizar las Indias Orientales.

Es más, el rey Juan III solicitó a los jesuitas que actuaran como "confesores" en la corte. Al principio, por humildad, lo rechazaron. Pero Ignacio de Loyola "resolvió sin vacilar que, si a todos los fieles procuramos hacer bien mediante el sacramento de la penitencia, no debíamos rehusar este beneficio a los príncipes, cuando precisamente la santificación de estos hombres influye tan saludablemente en provecho de la sociedad" (Lamet, 2004,191-2).

A partir de Juan III comenzó una larga "dinastía" de jesuitas "confesores" que, a lo largo de la Edad Moderna y en parte de la Edad Contemporánea, guiaron la conciencia de los monarcas europeos y que serán también consejeros de primer orden en asuntos eclesiásticos, interviniendo asimismo en el proceso de elección de los obispos y otras dignidades. Se convirtieron, en suma, en personalidades de gran influencia en el devenir político del Antiguo Régimen. Muchas veces fueron las "eminencias grises" de las cortes católicas.

A mediados del siglo XVIII, la actividad de la Compañía de Jesús en Portugal era similar a la de otros países católicos de Europa. Los jesuitas regentaban centros educativos dirigidos principalmente a las clases sociales más pudientes, en las urbes regentaban templos bien conocidos, algunos eran "confesores" o direc- 
tores espirituales de personalidades importantes de la aristocracia y su presencia misionera era también muy relevante en las colonias de ultramar. Se calcula (Astorgano Abajo, 2009, 266) que, en el momento de su expulsión, el número de jesuitas de la Asistencia de Portugal ascendería a más de 1700, de los que 817 residían en la metrópoli. En total y en 1762, (Madariaga en Pacheco y De Leyva, 1915, XL) el número de jesuitas se elevaba en todo el orbe a 22787, de los que cerca de 9000 pertenecían a la Asistencia de Alemania.

\section{LA POLÍTICA “REGALISTA" Y EL “ANTIJESUITISMO” DEL MARQUÉS DE POMBAL}

No puede entenderse la política portuguesa de mediados del siglo XVIII sin la figura del poderoso y controvertido Sebastião José de Carvalho e Melo, Marqués de Pombal y primer ministro del rey José I desde 1755. Antes de ser ministro había servido como embajador en Inglaterra y Austria. Puso todos sus esfuerzos, y desde las coordenadas de la filosofía política de la llustración, en incoar en Portugal las reformas económicas, administrativas y sociales que otros países de Centroeuropa estaban ya poniendo en marcha desde algunas décadas atrás.

Más aún, Pombal ha sido calificado repetidamente como uno de los mejores representantes del "despotismo ilustrado", a la vez que ha pasado asimismo a la historia como el máximo exponente del "antijesuitismo"; es decir, ha sido arquetipo de la aversión política a la Compañía de Jesús y característica de buena parte de los gobernantes europeos del "Siglo de las Luces". ${ }^{5}$

El Marqués de Pombal, al igual que la mayoría de los políticos que se enfrentaron a la Compañía de Jesús, no interpretó su postura como antirreligiosa. ${ }^{6}$ La mayoría de ellos eran católicos, también practicantes, y se sintieron respaldados por parte del clero de la época, que igualmente se identificaba en mayor o menor medida con el "antijesuitismo". Hubo, entre los representantes del "antijesuitismo", no cristianos como el gran filósofo Voltaire, pero también se contaban católicos devotos, como por ejemplo el rey español Carlos III. El "jansenismo" fue, por otro lado, la corriente teológica $-\mathrm{y}$ surgida esencialmente en Francia- más enfrentada con los jesuitas en el seno del catolicismo. ${ }^{7}$

En suma, a mitad del siglo XVIII no faltaban enemigos a la Compañía de Jesús tanto en Portugal como en otros países. Así también los jesuitas atribuían la persecución de la que eran víctimas a una conspiración bien planificada y organizada, apoyada por las cortes "regalistas" e ideada por los seguidores del "jansenis- mo", la masonería y en general los filósofos de la llustración (Giménez López, 2010, 251 - 80).

No hay ningún dato que induzca a pensar que el Marqués de Pombal se arrepintiera nunca de su política "antijesuita", lo cual no fue óbice para que muriera como católico y con el manifiesto reconocimiento a su trayectoria política por parte de significativos sectores del clero portugués. Tampoco hay constancia de que el rey José I sintiera nunca ningún remordimiento por expulsar a los jesuitas de su imperio. ${ }^{8}$

Aún hoy la figura del Marqués de Pombal genera, sin embargo, amplio debate entre los historiadores. De todos modos es compartido, y como describe uno de sus estudiosos, que "independientemente de haber sido buen o mal gobernante, fue claramente déspota, tirano en muchas de sus acciones, mas fue también un reformador y, sobre todo, un precursor del Portugal moderno" (Vicente, 2003, 21).

Pombal, y de acuerdo al pensamiento político del "despotismo ilustrado", creía en un poder absoluto y centralizado en la figura del monarca, no sometido ni a la influencia ni a la injerencia de la nobleza y el clero, a quienes creía casi siempre reaccionarios e inmovilistas. Para que el rey pudiera tomar y ejecutar eficazmente sus decisiones reformistas, debía sentirse libre de compromisos y ataduras frente a ambos estamentos. Pombal, como primer ministro, reaccionó con hostilidad y de modo implacable contra los que consideraba enemigos del rey José I. La sintonía entre ambos era bien conocida y fue creciendo con los años. Pombal era el hombre de confianza del rey, en cuyas manos depositaba los asuntos de Estado.

Por lo tanto, el conflicto político entre el Marqués de Pombal y los jesuitas ha de interpretarse naturalmente, y ante todo, en el contexto de las nuevas corrientes "regalistas" de la Ilustración. Para Pombal, la Compañía de Jesús era una amenaza a la autoridad absolutista y legítima del rey de Portugal. ${ }^{9}$

Para comprender el posicionamiento de la filosofía política de los jesuitas hay que tener en cuenta en primer lugar que desde tiempos de Ignacio de Loyola, y a diferencia del resto de institutos religiosos, los jesuitas tienen opción de profesar un cuarto voto de obediencia al Papa que les dispone para cualquier misión al servicio de la Iglesia Católica. Esto tuvo notable influencia en el discernimiento intelectual de los jesuitas en el plano político, que les condujo a subrayar la supremacía del Romano Pontífice sobre las monarquías y que se contraponía, claro está, a las corrientes "regalistas" características del "despotismo ilustrado". 
Enfrentarse, además, a la influencia de los jesuitas era asimismo un ataque indirecto al papado y más exactamente a su presencia política. ${ }^{10}$

En la mente del Marqués de Pombal como en la de otros muchos gobernantes ilustrados, y bajo la influencia del "galicanismo", estaba también la intención de crear "Iglesias católicas nacionales" más controladas por las monarquías que por el Romano Pontífice. De hecho, en 1760, un año después de decretar el destierro de los jesuitas y naturalmente a iniciativa del Marqués de Pombal, el nuncio apostólico fue expulsado de Portugal, lo cual implicaba ipso facto la ruptura de las relaciones diplomáticas entre el imperio luso y los Estados Pontificios o el mismo Papa.

Detrás por tanto, de la defensa de la supremacía del Papa que los jesuitas hacían, estaba también el interés por guardar la independencia y la libertad de la Iglesia Católica, en aras de evitar cualquier intromisión de carácter político y en concreto por parte de la corte.

Hay que añadir que el "despotismo ilustrado" no ignoraba tampoco la importante influencia de los jesuitas en la sociedad de su época y sobre todo entre la nobleza o las clases dirigentes. No hay que olvidar que los colegios y las universidades jesuitas se contaban entre las más selectas y excelentes de la Edad Moderna. Y familias enteras de la nobleza, la burguesía o los terratenientes eran educadas en ellos. ${ }^{11}$ La Compañía de Jesús, en un primer momento, rechazó dedicarse a la enseñanza, ${ }^{12}$ pero pronto fue inaugurando centros educativos a lo largo y ancho de la Europa católica o de los territorios coloniales. ${ }^{13}$

De hecho, con la expulsión de los jesuitas del imperio portugués, en 1759 , hemos de subrayar que la Compañía de Jesús abandonó 23 colegios en la metrópoli y, en Brasil, 17 colegios y seminarios además de 36 misiones (Brazão, 1982, 354 - 5).

El método educativo de la Compañía de Jesús, caracterizado en primer término por el acompañamiento individualizado del alumnado, heredado de la atención personalizada que guía la impartición de los Ejercicios Espirituales de Ignacio de Loyola, implicaba también una relación directa y estrecha de los jesuitas con los estudiantes y que a menudo se prorrogaba a lo largo de los años una vez que abandonaban los centros educativos. ${ }^{14}$ Así los jesuitas se convertían con frecuencia en directores espirituales o "confesores" de la elite política y económica de las naciones católicas, no solo de miembros de la corte. Era una influencia tan discreta como bien palpable.
Y no se ponía en duda, tampoco por parte de sus acérrimos enemigos como el Marqués de Pombal, la altura intelectual de los miembros de la Compañía de Jesús, que muchas veces lideraba el pensamiento católico y se hacía presente en multitud de disciplinas. La desaparición de los jesuitas de la enseñanza y del mundo de la cultura eliminaba, de este modo, un gran obstáculo para introducir en Portugal los principios del experimentalismo, del enciclopedismo y del "regalismo" que caracterizaron a la llustración o al "despotismo ilustrado".

Tales principios fueron, por ejemplo, los que calaron en la nueva orientación que la histórica Universidad de Coimbra empezó a tomar a partir de 1772, una vez que los jesuitas la habían abandonado (Viñao Frago, 1991, 299).

En suma, su influencia sobre las elites y su densa capacitación generaron gran animadversión hacia los jesuitas entre no pocos sectores políticos y culturales que, forjados en la era de la llustración, abogaban por una sociedad y un Estado menos clericales.

Llegados a este punto cabe preguntarse por qué fue Portugal, y no otro país católico, el primero que expulsó a los jesuitas. Es decir, qué hechos específicos se reprodujeron en Portugal y no en otras naciones, en la década de 1750, y que desembocaron en la disolución de la Compañía de Jesús.

Ciertamente en estos años tuvieron lugar acontecimientos concretos, y bien identificados, que acrecentaron el "antijesuitismo" del Marqués de Pombal y del rey José I. Son las razones sui generis que, en Portugal, desembocaron en el extrañamiento de los jesuitas. En síntesis podríamos hablar de dos hechos históricos sucesivos y en los cuales nos centraremos a continuación: El Tratado de los Límites y la sublevación de los guaraníes, en primer término, y el atentado contra la vida del rey José I y la culpabilización de los jesuitas, en segundo.

En las páginas siguientes analizaremos con detenimiento ambos episodios históricos.

\section{EL TRATADO DE LOS LÍMITES Y LA SUBLEVACIÓN DE LOS GUARANÍES}

La relación entre la Compañía de Jesús y la corona portuguesa comenzó a tensarse peligrosamente con ocasión del Tratado de los Límites, suscrito por las dos coronas de la península ibérica en 1750 . Este convenio quería poner fin a las disputas territoriales de ambos reinos en la zona meridional de América Latina y 
que se remontaban al Tratado de Tordesillas de 1494. El Tratado de los Límites o Tratado de Madrid supuso un intercambio de territorios pacífico y amistoso entre ambos reinos.

Principalmente hay que subrayar que a razón de este tratado, y a cambio de la colonia de Sacramento, España entregaba a Portugal una amplia franja de medio millón de kilómetros cuadrados en la parte oriental del río Uruguay y que incluía siete "reducciones" jesuitas pobladas por alrededor de 30000 guaraníes (Furlong en Marzal, 1992, 350). A su vez, esto implicaba que los jesuitas y los guaraníes debían abandonar tales "reducciones", a fin de asentarse en nuevos territorios bajo soberanía española.

De modo inmediato los jesuitas protestaron por las consecuencias que, sobre las "reducciones" guaraníes, el Tratado de los Límites iba a acarrear. En su hilo argumental, los jesuitas expusieron también a las autoridades españolas las desventajas que el acuerdo iba a suponer sobre los intereses políticos o económicos de la corona de Madrid y que, en cualquiera de los casos, iba a beneficiar más a Portugal (Makilcz Urquijo en Baltasar Maziel, 1988, 36 - 7).

Las "reducciones" comprendieron en total una treintena de pueblos misioneros bajo la tutela de la Compañía de Jesús, fundados a partir de los primeros años del siglo XVII, y habitados por los indígenas "guaraníes". Estas "reducciones" se distribuían entre los actuales Paraguay, Brasil y Argentina. Los jesuitas buscaron crear "sociedades ideales" gobernadas por los propios indígenas, pero desde la vigilante y paternalista mirada de la Compañía de Jesús. Las "reducciones" se sustentaron en una economía comunitaria, hasta el punto que algunos las han calificado de "experiencia pre socialista" o "socialismo cristiano". Las "reducciones" constituyeron una cultura y un sistema de organización social, político y urbano diseñado por jesuitas europeos pero que, como ha insistido la historiografía más reciente, el sustrato antropológico guaraní contribuyó a forjarlo de manera vital. ${ }^{15}$

Unos con admiración y otros de modo despectivo han denominado a lo largo del tiempo, a las "reducciones" jesuitas, como la "república guaraní". Algunos historiadores son de la opinión de que las "reducciones" jesuitas, y en concreto el hecho de que los guaraníes fueran "vasallos" del rey de España, sirvieron como muro de contención al deseo expansionista de los portugueses desde el Brasil meridional. Por ejemplo en palabras de J. Lacouture $(1993,563)$, "la república jesuita-guaraní fue creada o aceptada como un
Estado - tampón entre el imperio de los Habsburgo de España y los satélites turbulentos de Lisboa".

De todas las maneras la consolidación de las "reducciones" ha de entenderse asimismo en el afán de los jesuitas de proteger a la población indígena de las incursiones de los conocidos como "bandeirantes", procedentes de San Pablo de Piratininga (São Paulo) y dedicados a la "caza de esclavos". La historiografía, española por ejemplo, ha tratado de modo muy negativo a los "bandeirantes." debido a sus ataques indiscriminados contra los guaraníes y por potenciar el "mercado de esclavos". Pero, en Brasil, han logrado cierto reconocimiento histórico a razón de que sus expediciones dentro del continente contribuyeron notablemente a la expansión del país más allá de lo acordado por el Tratado de Tordesillas.

El agrupamiento de los guaraníes en "urbes", confiadas a la Compañía de Jesús, garantizaba la protección de la población indígena frente a los ataques de los "bandeirantes". Los jesuitas fortificaron las "reducciones", además de entrenar y armar a los guaraníes para su defensa frente a los ataques de los "bandeirantes". Tras la victoria de las milicias guaraníes en la batalla de Mbororé, acaecida en 1641 , se consolidó no solo el sistema de las "reducciones" sino que también se frenó la expansión portuguesa en aquel territorio. Por consiguiente la enemistad entre la América portuguesa y los jesuitas tenía, más de un siglo antes del Tratado de los Límites, un antecedente muy destacado.

Así y todo, la Compañía de Jesús era bien consciente de que sus buenas relaciones con los dos imperios ibéricos podía depender -en gran medida- del cumplimiento escrupuloso del Tratado de los Límites y más particularmente de no animar a los guaraníes, o no participar en revueltas con ellos, contra las tropas de Portugal y España. ${ }^{16}$

Tanto es así que el superior general de la orden solicitó "la pronto ejecución de las voluntades reales" (Woodrow, 1985, 54). Los indígenas se opusieron a abandonar las "reducciones" y en 1754 estalló la Guerra Guaranítica que se prolongó hasta 1756. La oposición armada de los guaraníes a los soldados españoles y portugueses fue en balde y se vieron obligados a abandonar las "reducciones". Los jesuitas (Revuelta González, 2007, 54), mientras tanto, fueron acusados tanto por portugueses como por españoles de alentar a los guaraníes a la lucha armada.

En estos mismos años surgió una campaña de desprestigio contra la Compañía de Jesús, auspiciada por la corte portuguesa y más exactamente por el Marqués 
de Pombal, que se extendió a gran parte de Europa. Por ejemplo se llegaron a publicar quizá más de veinte mil ejemplares de un folleto originalmente en portugués ("Relaçao Abreviada"), pero que se editó también en francés, alemán, italiano y latín, con el fin de criticar la presencia de los jesuitas en América del Sur y denunciando su supuesto poder político y económico (Fernández Arrillaga y García Arenas, 2009, 230 - 1). Incluso en la embajada portuguesa ante los Estados Pontificios, ubicada en Roma, pudo llegarse a imprimir literatura contra la Compañía de Jesús con el objeto de favorecer su difusión (Sánchez Montahud, 2000, 35).

Sin embargo no ha quedado constatado de modo suficiente que, dentro de la Compañía de Jesús, hubieran aparecido posturas individuales o de comunidades jesuitas de las "reducciones" que, desobedeciendo a los superiores de la orden, organizaran una resistencia armada junto a los guaraníes frente a las milicias portuguesas y españolas. ${ }^{17}$ Hecho que sí ocurrió décadas atrás, cuando los jesuitas participaron activamente en la lucha armada de los guaraníes frente a los "bandeirantes", y tal y como hemos ya explicado.

Otra cosa distinta es que hubiera jesuitas organizados que hicieran todo lo que estuviera en sus manos, por otras vías, para ralentizar el traspaso de las "reducciones" a la corona de Portugal, con la esperanza también de que se produjera la ruptura formal del tratado. De todos modos (Mörner, 1968, 136 - 7) lo más probable es que, aun considerando asimismo que hubo jesuitas dispuestos a desobedecer al superior general, predominara el deseo de convencer a los indios de abandonar pacíficamente las siete reducciones comprometidas con el objeto de evitar un derramamiento de sangre.

El Tratado de El Pardo de 1761, suscrito entre España y Portugal, vino a anular el Tratado de los Límites. El interés inicial de Carlos III, al poco de ser proclamado rey, de derogar el Tratado de los Límites implicó un deterioro de las relaciones con la corona portuguesa. Sin embargo, no muchos años después, Carlos III comenzó a tomar una posición cada vez más recelosa hacia los jesuitas -en el marco de la campaña "antijesuita" que recorrió Europa durante estos años- que le condujo a decretar su extrañamiento en 1767 . El rey español encontró en la monarquía portuguesa toda la colaboración en la expulsión de los jesuitas, hecho que también ayudó a favorecer las relaciones diplomáticas entre ambos países (García Arenas, 2008, 511 - 36).

La expulsión de los jesuitas de España implicó la sentencia de muerte de las "reducciones" guaraníes.
Al abandonar los jesuitas las "reducciones" entraron rápidamente en decadencia y nunca se recuperaron. Desapareció una cultura de siglo y medio de historia que despertó asimismo el interés y la admiración, incluso, de algunas de las figuras más representativas del "antijesuitismo". ${ }^{18}$

\section{EL ATENTADO CONTRA LA VIDA DEL REY JOSÉ I Y LA CULPABILIZACIÓN DE LOS JESUITAS}

En la madrugada del 3 de septiembre de 1758, y cuando viajaba de incógnito en un carruaje de regreso a los aposentos reales, el monarca José I fue víctima de un atentado contra su vida en el cual sufrió heridas leves. De inmediato el monarca, con la ayuda de su fiel ministro el Marqués de Pombal, puso en marcha las pesquisas para hallar a los culpables. Pronto los jesuitas fueron acusados de conspirar y participar en la organización de un "complot" para asesinar al rey. Como consecuencia de las detenciones que poco después se comenzaron a producir, más de medio millar (Crétineau - Joly, 1848, 53) de jesuitas llegaron a ser encarcelados.

Sin embargo, todavía hoy es un misterio no resuelto quiénes fueron realmente los autores materiales del atentado contra el rey, que fue herido en un brazo como consecuencia de un disparo, qué personas exactamente lo planificaron y qué pretendieron con su intento frustrado de homicidio.

¿Por qué los jesuitas eran, esta vez, acusados nada menos de intentar asesinar al monarca de Portugal? Era conocido por todos que la antipatía entre la Compañía de Jesús y el rey habían ido creciendo rápidamente desde su subida al trono en 1750, y tal y como hemos ido explicando. Y en el círculo "antijesuita" de la corte portuguesa, liderado por supuesto por el Marqués de Pombal, surgió una doble argumentación a fin de presentar a la Compañía de Jesús como culpable de conspirar contra la vida del monarca.

Una primera tesis por la cual se involucraba a la Compañía de Jesús en la gestación del atentado contra José I se basaba en la supuesta defensa que los jesuitas hacían del "regicidio", en la medida que se inspiraban en el pensamiento del filósofo español Juan De Mariana (1536 - 1624). De Mariana, una de las figuras intelectuales más brillantes de las primeras décadas de andadura de la Compañía de Jesús, dedicó parte de su obra a la teoría política y en la que trató someramente la cuestión del "tiranicidio". ${ }^{19}$

Es imaginable, en el contexto histórico del "despotismo ilustrado" europeo o en el momento más álgido 
del "regalismo", el impacto que en las cortes europeas hubo de causar las acusaciones -aunque pensemos que eran objetivamente infundadas- de que la Compañía de Jesús daba su respaldo institucional a un tipo de filosofía política que promovía el "regicidio". ${ }^{20}$

En otros países europeos, y en el marco de la campaña "antijesuita" impulsada principalmente por el Marqués de Pombal desde algunos años atrás, se difundió también que a los jesuitas arrestados en Portugal tras el atentado contra el rey se les habían encontrado documentos en los que abogaban a favor del "tiranicidio" (Mestre Sanchis, 1996, 102).

En segundo lugar -y más centrándonos en los hechos concretos que rodearon al atentado- hay que apuntar que, la noche en la que el asalto al carruaje se produjo, el rey regresaba de visitar a una mujer, Teresa de Tâvora, perteneciente a una de las más importantes e influyentes familias de la aristocracia portuguesa. ${ }^{21}$ Se decía, asimismo, que era amante del monarca. Además, y sobre todo por lo que nos atañe, su "confesor" era el conocido jesuita de origen italiano Gabriel Malagrida, de quien eran bien notorios sus enfrentamientos con el Marqués de Pombal.

Así que de acuerdo a la reconstrucción interesada del atentado que el Marqués de Pombal promovió, Teresa de Tâvora -instigada por el jesuita Malagrida y por su familia- habría informado del itinerario y de la hora de regreso de José I, a fin de que se preparara el atentado de modo concienzudo.

¿A qué se debía que el Marqués de Pombal y Malagrida mantuvieran malas relaciones? Para responder a esta pregunta debemos remontarnos hasta los sucesos inmediatamente posteriores al terrible terremoto de Lisboa. Cuando Lisboa amaneció, el día de Todos Los Santos de 1755, fue totalmente arrasada por un terremoto con una intensidad 9 en la entonces inexistente escala de Richter y que acabó con la vida de decenas de miles de habitantes. Europa no había conocido hasta entonces -y tampoco después- un desastre natural de estas dimensiones. ${ }^{22}$

Buena parte de la población portuguesa era supersticiosa y achacó la causa del terremoto a la ira de Dios. En particular, y en el contexto de la desolación lisboeta producida tras la catástrofe, emergió una figura antítesis del Marqués del Pombal y a quien, desde entonces, el ministro del rey José I contará entre sus mayores enemigos a batir: El jesuita Gabriel Malagrida. Este jesuita había trabajado como misionero en Brasil, desempeñando una labor apostólica muy fructífera a través por ejemplo de las "misiones populares". ${ }^{23}$
Malagrida salvó "milagrosamente" la vida por alterar sus costumbres cotidianas el día del terremoto de Lisboa (Bérault - Bercastel, 1854: 17) y sintió, posiblemente por ello, haber recibido una misión "mesiánica" entre las docenas de miles de víctimas del terremoto aun supervivientes. Y Malagrida y el Marqués de Pombal, desde posiciones contrapuestas o hasta enfrentadas, se convirtieron posiblemente en los principales protagonistas de la vida de Lisboa durante las semanas sucesivas al terremoto.

Malagrida salió rápidamente a las calles para predicar la conversión y la penitencia, solicitando a los ciudadanos que se retiraran a la oración, arrastrando con él a miles de personas. Mientras tanto el Marqués de Pombal, y desde los criterios científicos, técnicos y racionalistas que distinguieron a la filosofía de la llustración, puso todos sus esfuerzos en rescatar heridos, enterrar a los muertos y evitar epidemias, dar de comer a la población hambrienta y comenzar cuanto antes la reconstrucción de una ciudad derruida. Lo cierto es que la gran capacidad de liderazgo y gestión personal, que el Marqués de Pombal demostró durante la crisis del terremoto de Lisboa de 1755 , ha pasado a la historia como una de las mejores aportaciones de su gobierno, cuando no la que más. ${ }^{24}$

El jesuita Malagrida escribió la obra O Juízo da verdadeira causa do terremoto que padeceu a Corte de Lisboa no primeiro de novembro de 1755, en la que apuntó directamente al mal gobierno del Marqués de Pombal como causa que provocó el desastre. Para el Marqués de Pombal, el jesuita Malagrida entorpecía gravemente el saneamiento y la reedificación de la ciudad, además de atacar su política. Le acusó de fanático y solicitó -y logró- que el rey José I lo desterrara fuera de la capital del país, alejado tanto de la población como del ambiente cortesano.

Aunque Malagrida tenía ganado un prestigio importante en la Compañía de Jesús (como en otros sectores de la Iglesia Católica o de la sociedad portuguesa), no puede concluirse en absoluto que su actitud ante la catástrofe de Lisboa podría extenderse a la globalidad de los jesuitas, a pesar de lo señalado por algunos autores. ${ }^{25}$

De un modo u otro y tras el atentado contra el rey, el Marqués de Pombal encontró una nueva oportunidad para perseguir nuevamente a Malagrida, al resto de la Compañía de Jesús y a la nobleza más crítica con el gobierno del rey José I.

De hecho, el proceso contra la familia Tâvora constituyó uno de los episodios más oscuros del reinado de 
José I y del gobierno del Marqués de Pombal. No se siguieron suficientes garantías procesales y se dieron por válidos confesiones o testimonios bajo tortura. Como consecuencia, en enero de 1759 destacados miembros de esta familia aristócrata acabaron en el patíbulo, fueron ejecutados entre grandes tormentos y ante la presencia obligada de otros nobles. De esta manera el Marqués de Pombal pretendió dar una lección ejemplarizante a la nobleza más descontenta o díscola con su gobierno y que nunca estuvo conforme con su designación como primer ministro, pues también le consideraba indigno por formar parte de una "familia plebeya". Se llegó hablar, asimismo, de "terror pombalino" debido a las decididas persecuciones sin piedad que el marqués organizó contra sus enemigos. Además, la inclusión de los jesuitas en el proceso, acusados de ser autores intelectuales del atentado contra el rey, ha sido también considerada como uno de los exponentes que mejor reflejan las irregularidades que lo condujeron. ${ }^{26}$

Unos meses antes del atentado contra el rey, el patriarca de Lisboa -cardenal Saldahana- fue nombrado por el Papa Benedicto XIV visitador de la Compañía de Jesús en Portugal. Saldahana, clérigo cercano al marqués de Pombal y máxima figura de la jerarquía de la Iglesia Católica lusa, censuró a los jesuitas y evidenció la división del alto clero portugués respecto a la Compañía de Jesús. En sintonía con la campaña "pombalina" contra los jesuitas, el cardenal denunció los supuestos abusos de las actividades comerciales practicadas por los jesuitas. Les impidió continuar dedicándose al comercio y les amenazó con la excomunión en caso de desobediencia. ${ }^{27}$

Ciertamente la actitud de Saldahana es representativa de un número importante de obispos -de Portugal o de otros países- que sintonizaban con las doctrinas "regalistas" o que, al menos, se sentían agradecidos a las monarquías por haber sido promovidos a determinadas sedes episcopales y que, en consecuencia, aceptaban ser instrumentalizados en defensa de las políticas de la corte.

El Marqués de Pombal entregó a Malagrida a la Inquisición, en este tiempo ya bajo su influencia o incluso dominio, quien lo condenó a morir en la hoguera en 1761. El "caso Tâvora" restó, sin duda, popularidad al Marqués de Pombal y al rey José I, no solo en Portugal sino también en las cortes europeas y en los ambientes de la llustración. Respecto a la condena de Malagrida a morir en la hoguera, y cuando ya sufría enajenación mental, el rey francés Luis XV comentó (Cheke en Sauret, 2004, 54): "Es como si yo hubiera quemado al viejo loco del manicomio Petites quien afirma que es Dios Padre".

Unos pocos días después de la ejecución de los principales miembros de la familia Tâvora, y a través de una "carta real", el 19 de enero de 1759 todos los jesuitas fueron acusados de intentar asesinar al rey y, por lo tanto, debían considerarse prisioneros en sus residencias. Se solicitó a los obispos que censuraran a los jesuitas y, en el mes de abril y en carta al Papa Clemente XIII, se les calificó de "incorregibles". El embajador portugués ante la Santa Sede, por su parte, pidió al Papa que los jesuitas pudieran ser juzgados por "los tribunales reales". En junio de este mismo año los jesuitas fueron apartados de la enseñanza y se ordenó prender fuego a los libros utilizados en los centros educativos de la Compañía de Jesús. Finalmente y con la oposición del nuncio apostólico y del Papa Clemente XIII, y el mismo día que se cumplía el primer aniversario del atentado contra el rey, los jesuitas fueron declarados, en todo el territorio portugués, "desnaturalizados, proscritos y exterminados" (O’Neill y Domínguez (dirs.), 2001, 674).

Los jesuitas abandonaron Portugal y el Papa se sintió obligado a acogerlos en los Estados Pontificios. Clemente XIII, a diferencia de su sucesor en el solio pontificio Clemente XIV, sí defendió decididamente a los jesuitas. La campaña "pombalina" contra la Compañía de Jesús, entre tanto, no terminó con el extrañamiento de los jesuitas de Portugal. ${ }^{28}$ Tanto Pombal como su gabinete diplomático insistieron en las cortes católicas y en Roma de la necesidad de hacer desaparecer para siempre a la orden de Ignacio de Loyola.

La muerte en 1777 del rey José I provocó que el Marqués de Pombal enseguida cayera en desgracia en la corte. Para entonces, la orden de los jesuitas llevaba cuatro años suprimida por decisión del Papa Clemente XIV. Y el haber contribuido a ello había sido, para el Marqués de Pombal, un gran éxito diplomático y personal. No obstante, la subida al trono de la hija del rey María I, apodada "La Piadosa", supuso un giro en la política portuguesa y se paralizaron no pocas de las reformas incoadas por el Marqués de Pombal. Años atrás, María había también intercedido ante su padre por la vida de miembros de la familia Tâvora. Es más, se revisó el caso Tâvora y la familia logró ser rehabilitada. Al tiempo que sectores de la nobleza, que se habían sentido arrinconados cuando no perseguidos por el Marqués de Pombal, solicitaron que él fuera ahora procesado. Su avanzada edad evitó que acabara siendo enjuiciado y murió retirado de la vida pública en 1782 . 


\section{CONSECUENCIAS DE LA EXPULSIÓN DE LOS JESUITAS DE PORTUGAL Y PALABRAS FINALES}

La expulsión de los jesuitas de Portugal supuso uno de los triunfos más importantes de la política "regalista" del marqués de Pombal, que fue saludado en otras cortes europeas y que, más pronto que tarde, siguieron su ejemplo. A pesar de que el exilio de los jesuitas fue aplaudido por algunos sectores del catolicismo portugués, lo cierto es que también implicó la retirada de la Iglesia Católica de espacios misioneros muy relevantes o de otros de gran influencia política, educativa y cultural. Tensó hasta el límite las relaciones con la Santa Sede y fue también una maniobra para instaurar una especie de "galicanismo" portugués.

En realidad la expulsión de los jesuitas respondió a la campaña promovida por el Marqués de Pombal y que enseguida se extendió por otros países europeos. Sin embargo no han podido ser adecuadamente probadas ni la implicación de los jesuitas en la rebelión armada de los guaraníes, como consecuencia del Tratado de los Límites de 1750, ni aún menos su involucración en el atentado de 1758 contra la vida del rey José I.

Sobre todo para los sectores más clericales de la sociedad portuguesa, y para amplios ámbitos de la nobleza, la expulsión de la Compañía de Jesús fue otro motivo para distanciarse todavía más de la monarquía de José I.
Por otro lado, el vacío que los jesuitas dejaron en el plano de la enseñanza, sobre todo al abandonar sus selectos colegios, no fue cubierto en general por educadores de tanto prestigio. No obstante, y de modo indirecto, la disolución de la Compañía de Jesús abrió paso a una mayor presencia de otras órdenes religiosas que la sustituyeron en parte de sus ministerios. La desaparición de los jesuitas de territorio portugués favoreció asimismo, y de la mano del Marqués de Pombal, la penetración de las ideas reformistas de la llustración en el campo de las ciencias y la cultura, susceptibles a ser combatidas desde el atalaya intelectual de la orden de Ignacio de Loyola.

Tampoco podemos ignorar que la expulsión de los jesuitas implicó, de modo análogo, un primer hito en el proceso de secularización de la vida cultural y política del país, y en particular en la separación de la Iglesia y el Estado, que se iría a consolidar a lo largo del siglo XIX.

Finalmente cabe recordar que los jesuitas no regresaron a Portugal hasta más de medio siglo después, una vez que el Papa Pío VII restauró la Compañía de Jesús en todo el orbe, inaugurándose así también una nueva etapa de relaciones de la orden de Ignacio de Loyola con el absolutismo monárquico que -a diferencia de la época que hemos estudiado- tuvo más de sintonía que de relación tormentosa. 
1 "No basta extinguir los Jesuitas, es menester extinguir el Jesuitismo; y en los Países, donde han estado la memoria de su doctrina, política, y costumbres", señaló en 1767 Manuel de Roda, ministro del rey español Carlos III (Pinedo Iparraguirre, 1996, 554).

2 La elaboración de este artículo coincide con los actos conmemorativos, en 2014, de los doscientos años de la restauración de la Compañía de Jesús. En todo el mundo los jesuitas han organizado eventos para celebrar tal efemérides. El jesuita y rector de la Universidad de Deusto, J. Ma. Guibert (2014, 4 - 5), se refería a este acontecimiento de la siguiente manera:

"Los cuarenta años de supresión oficial (de 1773 a 1814) permiten sacar algunas lecciones de las luces y sombras de nuestro pasado. Algunas son las que siguen. La fortaleza que mostraron ante las dificultades; el reconocimiento y examen de los errores cometidos; la solidaridad y cuidado entre ellos, compartiendo lo poco que tenían; la perseverancia, la mayoría de ellos, en su vocación como jesuitas; su fidelidad a la Iglesia; la capacidad de recuperación después de haber perdido tanto y de empezar de nuevo; la vuelta a vivir juntos, tras años de aislamiento y separación; la inmensa creatividad del siglo XIX en el nacimiento de tantos colegios, santuarios, publicaciones, prácticas pastorales".

3 El Papa dejó escrito, en este documento, que "nuestros muy amados en Cristo hijos los reyes de Francia, de España, de Portugal, y de las dos Sicilias, se han visto absolutamente precisados á hacer salir, y á expeler de sus Reynos y dominios á los individuos de la Compañía; considerando que este era el único remedio que quedaba para ocurrir á tantos males, y totalmente necesario para impedir que los pueblos Cristianos no se desaviniesen, maltratasen, y despedazasen entre si en el seno mismo de la Santa Madre Iglesia" (Benimeli Ferrer, 1998, 349).

4 Los obispos portugueses que más criticaron la decisión de expulsar a los jesuitas fueron los que regían diócesis de ultramar, como el arzobispo de $\mathrm{Ba}$ hía o el prelado de Cochin (Menéndez Pelayo, 1992, 593). Eran bien conscientes del daño que el extrañamiento de los jesuitas hacía al apostolado misionero. En algunos territorios de ultramar, pertenecientes a los imperios portugués, español o francés, la presencia misionera era solo atribuible a la Compañía de Jesús.

5 El "antijesuitismo" se fue a extender también más allá de la llustración, sobre todo en el siglo XIX, con sus propios matices y versiones. Por ejemplo a finales del siglo XIX, el escritor y socialista español F. Garrido (1881, 108 - 9), en su divulgada obra sobre los jesuitas, se refería así al episodio de la expulsión de la Compañía de Jesús de Portugal: "La Compañía de Jesús era, pues, señora de Portugal y sus dominios; pero el marqués de Pombal era hombre de genio extraordinario, y se propuso librar a su patria del yugo de la Compañía, diciendo que Portugal era de los portugueses y no una colonia del General de los jesuitas y del Papa".

6 Como Paulino Castañeda Delgado y Pilar Hernández Aparicio señalan, "Ias acusaciones contra las doctrinas jesuíticas tenían más política circunstancial que de peligro real para la fe y la moral; suprimir estas enseñanzas interesaba a aquellos ministros por razones políticas, y no por defender la fe y la moral, aun cuando se alegaran como razones fundamentales de la expulsión y la extinción" (Acevedo, 2012, 21).

7 La introducción del "jansenismo" en Portugal se empezó a producir, sobre todo, con ocasión de la expulsión de Portugal de los jesuitas y del nuncio del Papa (Dos Santos, 2007, 12 - 3).

8 Exponente del continuado "antijesuitismo" del rey es la conversación que mantuvo con el Marqués de Almodóvar y embajador de España en la corte de Lisboa, poco después de que Carlos III expulsara a los jesuitas de los territorios españoles. Durante la audiencia al embajador, el rey José I acusó a los jesuitas de ser culpables de los desencuentros entre las coronas de España y Portugal y de ponerse del lado de Inglaterra para neutralizar la presencia de su imperio en América. Es más, el rey sospechaba nada menos que los jesuitas iban a abandonar el catolicismo para abrazar el anglicanismo (Giménez López, 2001, 337).

9 Es importante recordar, no obstante, que los jesuitas respaldaron con claridad -un siglo antes- a la nueva monarquía portuguesa en su guerra de independencia respecto a España. Por ejemplo, y como J. Burrieza Sánchez (2008a, 220) recordaba, "la Compañía, en su provincia de Portugal, había contribuido con la palabra y también con cinco mil cruzados a los gastos de la guerra contra España".

10 En las teorías antimonárquicas los jesuitas fueron a coincidir también con sus mayores opositores en materia teológi$\mathrm{ca}$, como eran los pensadores calvinistas. Por ejemplo el rey Jacobo I de Inglaterra hablaba así de la filosofía política de la Compañía de Jesús: "Los jesuitas no son sino papistas puritanos" (Sabine, 1992, $287-9)$.

11 Sin embargo en opinión de algún historiador "todos los Colegios de la antigua Compañía, siglos XVI al XVIII inclusive, eran externados gratuitos" (Fernández en Kolvenbach, 1990, 8). Por lo tanto, la mayor presencia de las clases más privilegiadas en buen número de aulas jesuitas, al menos hasta los años de la disolución de la orden, debía explicarse principalmente en base a otros factores que no son económicos y, en especial, al deseo de formar e influenciar a las elites sociales.

12 En 1541, en una primera redacción de las Constituciones de los jesuitas, se indicó expresamente el deseo de "no estudios ni lecciones en la Compañía" (Batllori en Fundación Santa María, 1993, 57 - 8).

13 Podemos apuntar que a la muerte de Ignacio de Loyola, ocurrida en 1556, 35 de los 40 colegios -que él personalmente había aprobado- continuaban funcionando. Cuatro decenios más tarde el número de colegios se elevaba ya a 245 (Comisión Nacional de Educación SJ, 1986, 51).

14 El propio Ignacio de Loyola quiso atender, en persona, a todos los candidatos que iban a ingresar en la Compañía de Jesús, hasta el punto que muchos de ellos tuvieron que guardar largos tiempos de espera para ser recibidos. Asimismo, reclamaba a los profesores y responsables (rectores, profesores,...) que cuidasen de modo personal ("cura personalis") a todos los estudiantes, fuesen internos o externos (Ocampo Flórez, 2002, 10).

15 Por ejemplo G. Wilde (2012: 197) hablaba de las "reducciones" "como el resultado complejo de singulares procesos de 
etnogénesis que, en distintos niveles o escalas, expresaron la interacción negociada entre religiones y líderes nativos, contradicciones entre los sacerdotes y otros sectores de la sociedad y la Iglesia colonial (incluidas otras órdenes religiosas), adaptaciones al medio local y apropiación y resignificaciones que definieron espacios indígenas autónomos".

16 Hay que afirma con contundencia que el confesor del rey de España Fernando $\mathrm{VI}$, el influyente jesuita Francisco de Rávago, no fue informado de las gestiones que condujeron a la firma del Tratado de Madrid (Burrieza Sánchez, 2007, 384). Tampoco está claro con qué ímpetu o energía Rávago defendió -ante Fernando VI- los intereses de los jesuitas y de las "reducciones". Pero lo cierto es que los enemigos de la Compañía de Jesús se hicieron con cartas del confesor del rey de España que divulgaron y en las que Rávago animaba, nada menos, a desobedecer el Tratado de los Límites. Esta fue la razón por la cual Fernando VI prescindió de su confesor y así cayó en desgracia. El Marqués de Pombal, a través del embajador de Portugal en la corte de Madrid, también incitó a Fernando VI a separarse de Rávago (Martínez Peñas, 2007, 622 - 8).

17 La reconocida y divulgada película "La Misión" de 1986, dirigida por Roland Roffé y que relata el episodio del "Tratado de los Límites", da otra visión que no se ajusta a la realidad. Para un análisis histórico del film véase, por ejemplo, $M$. Martínez Gomis (1999).

18 Por ejemplo el filósofo francés Voltaire, y también uno de los mejores representantes de la llustración, llegó a señalar lo siguiente sobre las "reducciones": "Las reducciones aparecen como un triunfo de la humanidad; parecen expiar la crueldad de los primeros conquistadores, han dado al mundo un nuevo espectáculo" (Pinedo Noriega, 2001, 61).
19 "Si (...) no hubiere otro modo mas oportuno de defenderse, entonces por el mismo derecho de defensa propia y por autoridad propia, se podrá quitar la vida al príncipe, declarado enemigo público" (De Mariana, 1845, 76). Estas palabras pertenecen a una obra de politología dirigida, además, al rey español Felipe III.

20 Ante la situación tan delicada o comprometida en la que la Compañía de Jesús se veía a razón de los escritos que defendían el "tiranicidio", el superior general Claudio Aquaviva, que gobernó la orden de Ignacio de Loyola a caballo de los siglos XVI y XVII, hubo ya de impedir que los jesuitas enseñaran o publicaran libro alguno en donde declararan como legítimo el acabar con la vida de un gobernante, por muy tirano que fuera (Burrieza Sánchez, 2008b, 261).

21 Sin embargo, durante estas décadas, tanto la familia Tâvora como otras pertenecientes a la aristocracia portuguesa no destacaban por su poder económico, debido al nivel de endeudamiento significativo al que tenían que hacer frente (Benavente Rodrigues, 2010, 27 - 59).

$22 \mathrm{El}$ inesperado y trágico terremoto de Lisboa conmocionó no solo a Portugal, sino también a la sociedad europea de su tiempo. El debate intelectual o filosófico, acerca del origen y el sentido del mal, alcanzó gran protagonismo en el continente. Es más, se llega a apuntar que el terremoto de Lisboa dio el espaldarazo definitivo a la "teodicea", es decir, a la disciplina filosófica dedicada a discernir sobre la causa o el significado del mal. Asimismo el terremoto animó, y también a iniciativa del Marqués de Pombal, la investigación científica a fin de explicar racionalmente y predecir las catástrofes naturales de esta magnitud, en el contexto histórico de las nuevas tendencias de búsqueda del conocimiento del "Siglo de Las Luces" o de la llustración. Sobre las consecuencias del terremoto de Lisboa sobre la evolución de la filosofía y sobre todo la ciencia, véase por ejemplo A. Alberola Romá (2005).

23 La buena fama de Malagrida, como misionero y predicador, llegó también a oídos de la corte portuguesa. Así Malagrida fue recibido con todos los halagos por el rey Juan $V$ en Lisboa, a quien atendió como sacerdote en los últimos momentos de su vida, en el verano de 1750. Poco tiempo después la madre del rey José I requirió otra vez la presencia en palacio del carismático y piadoso jesuita (Valverde, 2012, 196).

24 En una de las biografías más divulgadas del Marqués de Pombal, elaborada a principios del siglo $\mathrm{XX}$, el autor se refería así a su figura en el episodio del terremoto de Lisboa: "Después de los siglos que nos separan de lo sucedido, la imaginación popular ve aún al super hombre, Sebastião José de Carvalho, emergiendo él solo del humo de la catástrofe" (D’Azevedo, 1922, 143).

25 Véase, por ejemplo, R. Peñalta Catalán $(2009,194)$.

26 Entre las últimas investigaciones que analizan el "caso Tâvora", y así también las acusaciones vertidas contra los jesuitas, véase por ejemplo P. W. Cardoso (2011).

27 A este respecto véase por ejemplo J. E. Franco $(2006,172$ - 3)

28 No pocos jesuitas, de Portugal o de otros países, respondieron al Marqués de Pombal con sátiras y críticas acerbas. Podemos hasta decir que, por parte de los jesuitas, hubo también una campaña contra el "Gran Marqués". Le achacaban el pertenecer a una familia judeoconversa o el haberse imbuido de ideas protestantes, debido a que permitió la apertura de iglesias de este culto en Lisboa o a que intentó que la sucesora al trono contrajera matrimonio con el duque de Cumberland (García Arenas, 2012, $1817-21$ ) 
Acevedo, E. O. (2012). "Sobre el ataque a los jesuitas ¿una variante?". Temas de historia argentina y americana, no 20 , pp. $15-21$.

Aguirre Beltrán, C. (1999). “La expulsión de los jesuitas y la ocupación de sus bienes". Cuadernos del archivo histórico universitario, no 4, Puebla: Benemérita Universidad Autónoma de Puebla - Gobierno del Estado de Puebla.

Alberola Romá, A. (2005). "El terremoto de Lisboa en el contexto del catastrofismo natural en la España de la primera mitad del siglo XVIII". Cuadernos dieciochistas, $\mathrm{n}=6$, pp. $19-42$.

Alonso Romo, E. J. (2005). Simón Rodrigues. Origen y progreso de la Compañía de Jesús. Estudio introductorio, traducción a partir de los originales portugués y latino, y notas. Bilbao - Santander: Mensajero - Sal Terrae.

Astorgano Abajo, A. (2009). "Esbozo de la literatura de los jesuitas portugueses expulsos". História Unisinos, vol. 3, № 13, Septiembre - Diciembre, pp. 265 - 83

Baltasar Maziel, J. (1988). De la justicia del Tratado de Límites de 1750. Estudio preliminar por José M. Makilcz Urquijo. Buenos Aires: Academia Nacional de la Historia.

Benavente Rodrigues, M. (2010). "Grandes de Portugal no século XVIII. Inventários da Casa de Távora, Atouguia e Aveiro (1758 - 1759)". Pecvnia, no 11, Julio Diciembre, pp. $27-59$.

Benimeli Ferrer J. A. (1998). La expulsión y extinción de los jesuitas según la correspondencia diplomática francesa. Tomo III 1770 - 1773. Zaragoza - San Cristóbal: Universidad de Zaragoza - Universidad Católica del Táchira.

Bérault - Bercastel, A. H. (1854). Historia general de la Iglesia, desde la predicación de los apóstoles, hasta el pontificado de Gregorio XVI. Tomo VII. Madrid: Imprenta de Ancos.

Brazão, E. (1982). "Pombal e os jesuítas". Revista de História das Ideas, tomo I, vol. 4, pp. $329-65$.

Burrieza Sánchez, J. (2007). Jesuitas en Indias: Entre la utopía y el conflicto. Trabajos y misiones de la Compañía de Jesús en la América Moderna. Valladolid: Universidad de Valladolid.

Burrieza Sánchez, J. (2008a). “La Compañía de Jesús y la defensa de la monarquía hispánica". Hispania Sacra, vol. LX, n으 121, Enero - Junio, pp. 181 - 229.

Burrieza Sánchez, J. (2008b). "Los jesuitas como fuerza intelectual política”. En F. J. Aranda Pérez y J. Damião Rodrigues (Coords.), De Re Publica Hispaniae: una vindicación de la cultura política en los reinos ibéricos en la primera modernidad (pp. 227 -63). Madrid: Sílex.

Cardoso, P. W. (2011). D. Joao de Almeida Portugal e a Revisao do Processo dos Távoras: conflictos, intrigas e linguagens políticas em Portugal nos finais do Antigo Regime (c.1777 - 1802). (Tesis inédita de doctorado). Universidade Federal Fluminense - Centro de Estudos Gerais Instituto de Ciências Humanas e Filosofia, Niterói.

Comisión Nacional de Educación SJ (1986). Características de la educación de la Compañía de Jesús.

Crétineau - Joly, J. (1848). Clemente XIV y los jesuitas, o sea historia de la destrucción de los jesuitas. $2^{2}$ edición. Madrid: Nicolás de Castro Palomino.

D’Azevedo, J. L. (1922). O Marquês de Pombal e a sua Época. 2a edición. Rio de Janeiro: Annuário do Brasil.

De Mariana, J. (1845). Del rey, y de la institución de la dignidad real. Tratado dividido en tres libros. Madrid: Imprenta de la sociedad literaria y tipográfica.

Dos Santos, C. (2007). O Jansenismo em Portugal. Porto: Faculdade de Letras da Universidade do Porto - Departamento de História e de Estudos Políticos e Internacionais.

Fernández Arrillaga, I. y García Arenas, M (2009). "Dos caras de una misma expulsión: el destierro de los jesuitas portugueses y la reclusión de los misioneros alemanes". Hispania Sacra, vol. LXI, no 123, Enero - Junio, pp. 227 - 56.

Franco, J. E. (2006). "O terramoto pombalino e a campanha de "desjesuitização"de Portugal". Lusitania sacra, no 18 , 2a série, pp. $147-218$

Fundación Santa María (1993). Historia de la educación en España y América. La educación en la España Moderna (siglos XVI - XVIII). Madrid: SM - Morata.

García Arenas, M. (2008). “La colaboración hispano - portuguesa contra la Compañía de Jesús (1767 - 1768)". En Instituto de Estudios Vascos, Esteban de Terreros y Pando: vizcaíno, polígrafo y jesuita. III
Centenario: 1757 - 2007 (pp. 511 - 36). Bilbao: Universidad de Deusto.

García Arenas, M. (2012). “La proyección del antijesuitismo portugués en España (1758 - 1762)". En J. Martínez Millán; H. Pizarro Llorente y E. Jiménez Pablo (Coords.), Los jesuitas. Religión, política y educación (siglos XVI - XVIII) (pp. 1811 - 42). Tomo III. Madrid: Universidad Pontificia Comillas.

Garrido, F. (1881). iPobres jesuitas! seguida de la Monita Secreta, o Instrucciones ocultas de los jesuitas, por primera vez publicadas en castellano. 2a edición. Madrid: Imprenta, Calle de Mendizabal, núm. 22.

Giménez López, E. (2001). "Portugal y España ante la extinción de los jesuitas". En M. Tietz (Ed.), Los jesuitas españoles expulsos. Su imagen y su contribución al saber sobre el mundo hispánico en la Europa del siglo XVIII (pp. 337 - 57). Madrid - Frankfurt: Bibliotheca Ibérico / Americana - Vervuert.

Giménez López, E. (2010). “Los jesuitas y la teoría de la conspiración". En E. Giménez López (Ed.), Aspectos de la política religiosa en el siglo XVIII: Estudios en homenaje a Isidoro Pinedo Iparraguirre S.J. (pp. 251 - 80). Alicante: Publicaciones de la Universidad de Alicante.

Guibert, J. Ma . (2014). Intervención del Rector en el acto académico de la Festividad de Santo Tomás de Aquino. Paraninfo de la Universidad de Deusto, Bilbao, $28-1-2014$.

Kolvenbach, P. H. (1990). “La Universidad: espacio para la unidad de las ciencias". Orientaciones Universitarias, $\mathrm{n}$ 응 4 , pp. $5-24$.

Lacouture, J. (1993). Jesuitas. I. Los conquistadores. Barcelona - Buenos Aires - Mexico: Paidós.

Lamet, P. M. (2004). Yo te absuelvo, Majestad. Confesores de reyes y reinas de España. Madrid: Temas de hoy.

Martínez Gomis, M. (1999). "El ocaso de la compañía de Jesús en América Latina. La misión". En J. Uroz (Ed.), Historia y cine. Alicante: Universidad de Alicante.

Martínez Peñas, L. (2007). El confesor del Rey en el Antiguo Régimen. Madrid: Editorial Complutense - Colegio Universitario de Segovia.

Marzal, M. M. (1992). La utopía posible. Indios y Jesuitas en la América Colonial. 
Tomo I. Brasil, Perú, Paraguay y Nuevo Reino. Lima: Pontificia Universidad Católica del Perú - Fondo Editorial.

Menéndez Pelayo, M. (1992). Historia de los heterodoxos españoles. Tomo II. Madrid: Consejo Superior de Investigaciones Científicas.

Mestre Sanchis, A. (1996). "Reacciones en España ante la expulsión de los jesuitas de Francia". Revista de Historia Moderna, no 15, pp. $101-28$.

Mörner, M. (1968). Actividades políticas y económicas de los jesuitas en el Río de la Plata. La era de los Habsburgos. Buenos Aires: Paidós.

O’Neill, C. E. y Domínguez, J. Mạ. (dirs.) (2001). Diccionario histórico de la Compañía de Jesús. Biográfico - Temático. Tomo I. Madrid - Roma: Universidad Pontificia Comillas - Institutum Historicum.

Ocampo Flórez, E. (2002). “Nuestra propuesta pedagógica: una herencia de la Ratio". Seminario AUSJAL sobre Identidad, Espiritualidad y Universidad. Universidades del Cono Sur. Montevideo: Universidad Católica del Uruguay.

Pacheco y De Leyva, E. (1915). El cónclave de 1774 a 1775. Acción de las cortes ca- tólicas en la supresión de la Compañía de Jesús según documentos españoles. Madrid: Junta para ampliación de estudios e investigaciones científicas - Escuela Española en Roma.

Peñalta Catalán, R. (2009). "Voltaire: una reflexión filosófico-literaria sobre el terremoto de Lisboa de 1755". Revista de Filología Románica, vol. 26, pp. $187-204$.

Pinedo Iparraguirre, I. (1996). El Antiguo Régimen, el Papado y la Compañía de Jesús (1767 - 1773). San Cristóbal: Universidad Católica del Táchira.

Pinedo Noriega, I. (2001). "Las Reducciones del Paraguay". Anales de mecánica y electricidad, vol. 78, no 1, pp. 50-61.

Revuelta González, M. (2007). “Jesuitas en América. Utopía y realidad en las reducciones del Paraguay". En Forum Deusto (Ed.), Jesuitas: una misión, un proyecto. Bilbao: Universidad de Deusto, pp. $33-57$.

Sabine, G. (1992). Historia de la teoría política. México: Fondo de Cultura Económica.

Sánchez Montahud, A. (2000). "Las relaciones entre Nápoles y la Santa Sede en la correspondencia del cardenal To- rrigiani con el nuncio de España (1758 - 1762)". Revista de Historia Moderna, no 18 , pp. $27-40$.

Sauret, B. A. (2004). Las cosas de estotro mundo: Cardiel y Pombal, utopistas, frente a la guerra guaranítica. Georgia: University of Georgia.

Valverde, N. (2012). Un mundo en equilibrio. Jorge Juan (1713 - 1773). Madrid: Fundación Jorge Juan - Marcial Pons Historia.

Vicente, A. P. (2003). "Marquês de Pombal: um governante controverso". Revista Camões, no $15-16$, pp. $17-21$.

Viñao Frago, A. (1991). "Sistema educativo nacional e ilustración. Un análisis comparativo de la política educativa ilustrada". En Varios Autores, Sociedad, cultura y educación (pp. 283 - 314). Madrid: Universidad Complutense de Madrid.

Wilde, G. (2012). "Las misiones jesuíticas de Paraguay: Imaginarios políticos, etnogénesis y agencia indígena". En A. Coello, J. Burrieza y D. Moreno (Eds.), Jesuitas e imperios de ultramar. Siglos XVI - XX (pp. 181 -98). Madrid: Ediciones Sílex.

Woodrow, A. (1985). Los jesuitas. Historia de un dramático conflicto. Barcelona: Planeta. 